\title{
PENGABDIAN MASYARAKAT MENUJU DESA PAMEGARSARI YANG MANDIRI MELALUI PENINGKATAN PENDIDIKAN
}

\author{
Fety Fatimah ${ }^{1}$, Abdul Latif, Biella Salsabila ${ }^{2}$ \\ fety.fatimah@ft.uika-bogor.ac.id \\ Dosen Fakultas Teknik ${ }^{1}$, Mahasiswa KKN Kelompok 12 Tahun $2017^{2}$
}

\begin{abstract}
ABSTRAK
Pendidikan adalah upaya mengembangkan potensi-potensi manusiawi peserta didik baik potensi fisik potensi cipta, rasa, maupun karsanya, agar potensi itu menjadi nyata dan dapat berfungsi dalam perjalanan hidupnya sebagai individu dan masyarakat. Dasar pendidikan adalah cita-cita kemanusiaan universal. Pendidikan bertujuan menyiapkan pribadi dalam keseimbangan, kesatuan. organis, harmonis, dinamis. guna mencapai tujuan hidup kemanusiaan. Oleh sebab itu, perguruan tinggi berupaya mewujudkan bibit-bibit penerus bangsa berkualitas secara nyata dengan melaksanakan berbagai upaya strategis bagi mahasiswanya. Seluruh upaya yang digariskan oleh sebuah perguruan tinggi seyogianya tidak terlepas dari visi dan misi perguruan tinggi sebagaimana yang lebih dikenal dengan Tri Dharma Perguruan Tinggi. Tri Dharma Perguruan tinggi merupakan jargon yang semestinya didengungkan dengan tiga aspek sebagai acuannya, yakni Pendidikan dan Pengajaran, Penelitian dan Pengembangan, dan Pengabdian Kepada Masyarakat.
\end{abstract}

\section{Kata Kunci : Pendidikan, Perguruan Tinggi, Potensi.}

\section{PENDAHULUAN}

Kecamatan parung membawahi 23 desa. Dan desa parung termasuk desa yang cukup pesat pertumbuhan penduduk nya disamping wilayah nya juga hampir mencapai 550 Ha. Atas dasar itulah pemerintah desa parung beserta seluruh tokoh masyarakat mengambil kebijakan desa parung harus di mekarkan. Memiliki luas wilayah 266, 068 Ha. Dan berbatasan sebagai berikut:

\begin{tabular}{|c|l|c|}
\hline No & Keterangan & Berbatasan \\
\hline 1 & Utara & Desa Parung \\
\hline 2 & Selatan & Desa Jabon Mekar \\
\hline 3 & Barat & Desa Waru Jaya \\
\hline 4 & Timur & $\begin{array}{c}\text { Desa Citayam/ Tajur } \\
\text { Halang }\end{array}$ \\
\hline
\end{tabular}

Antara Desa Citayam dan Desa Pamegarsari membujur dari selatan ke utara sungai Ciangke, jalan negara antara desa jabon mekar dan desa parung kurang lebih $3 \mathrm{~km}$. Dengan memiliki luas pemukiman $115 \mathrm{Ha}$, pertanian $13 \mathrm{H}$. Persawahan 2 Ha. Ladang 51 ha. Pemakaman 7 ha. Jalan desa 3.068 ha. Dan memiliki situ lebak wangi seluas 5,3 ha.

Terbentuknya Desa Pemagarsari, Lajunya perkembangan penduduk dan luasnya wilayah desa parung, ada banyak hal-hal yang tidak terjangkau oleh pemerintahan Desa Parung sehingga pada tahun 1982 dari hasil kebijakan-kebijakan para pemuka dan tokoh masyarakat desa parung serta keinginan sebagaian masyarakat untuk diadakan pemekaran. Di desa parung ada sebuah kampung yang 
bernama pamegarsari dan kampung lebak wangi. Berdasarkan nama kampung tersebut oleh masyarakat diusulkan untuk dijadikan desa pamekaran ke pemerintahan kabupaten Bogor, yang akhirnya dari kedua kampung tersebut salah satunya dijadikan desa pemekaran, yaitu kampung pamegarsari, maka pada tahun 1982 terbentuklah desa pamegarsari.

\section{Jumlah Penduduk}

\begin{tabular}{|c|l|c|}
\hline No & Jenis Kelamin & Jumlah \\
\hline 1 & Laki-Laki & 6.989 \\
\hline 2 & Perempuan & 7.277 \\
\hline
\end{tabular}

\section{Pendidikan}

\begin{tabular}{|c|l|c|}
\hline No & Tingkat Pendidikan & Jumlah \\
\hline 1 & SD & 5.625 \\
\hline 2 & SMP & 2.500 \\
\hline 3 & SMA & 3.251 \\
\hline 4 & Akademik (D1-D3) & 99 \\
\hline 5 & Sarjana (S1-S3) & 435 \\
\hline 6 & Tidak Tamat SD & 267 \\
\hline
\end{tabular}

Mata Pencaharian

\begin{tabular}{|c|l|c|}
\hline No & Pekerjaan & Jumlah \\
\hline 1 & Petani & 67 \\
\hline 2 & Pedagang & 211 \\
\hline 3 & PEGAWAI NEGERI & 69 \\
\hline 4 & TNI/POLRI & 3 \\
\hline 5 & PENSIUNAN/PURNA & 360 \\
& WIRAWAN & \\
\hline 6 & PEGAWAI SWASTA & 200 \\
\hline 7 & BURUH PABRIK & 30 \\
\hline 8 & PENGRAJIN & 10 \\
\hline 9 & TUKANG BANGUNAN & 50 \\
\hline 10 & PENJAHIT & 50 \\
\hline 11 & TUKANG LAS & 20 \\
\hline 12 & TUKANG OJEG & 20 \\
\hline 13 & BENGKEL & 20 \\
\hline 14 & SUPIR ANGKUTAN & 20 \\
\hline 15 & LAIN - LAIN & 12.347 \\
\hline
\end{tabular}




\section{METODE PENGABDIAN}

Pelaksanaan KKN di Desa Waru Rw06 ini terhitung selama 7 Agustus-7 September 2017 dengan tahapan pelaksanaan dengan hitungan permingggu berjumlah 4 tahapan, Adapun tahapan pelaksanaan sebagai berikut:

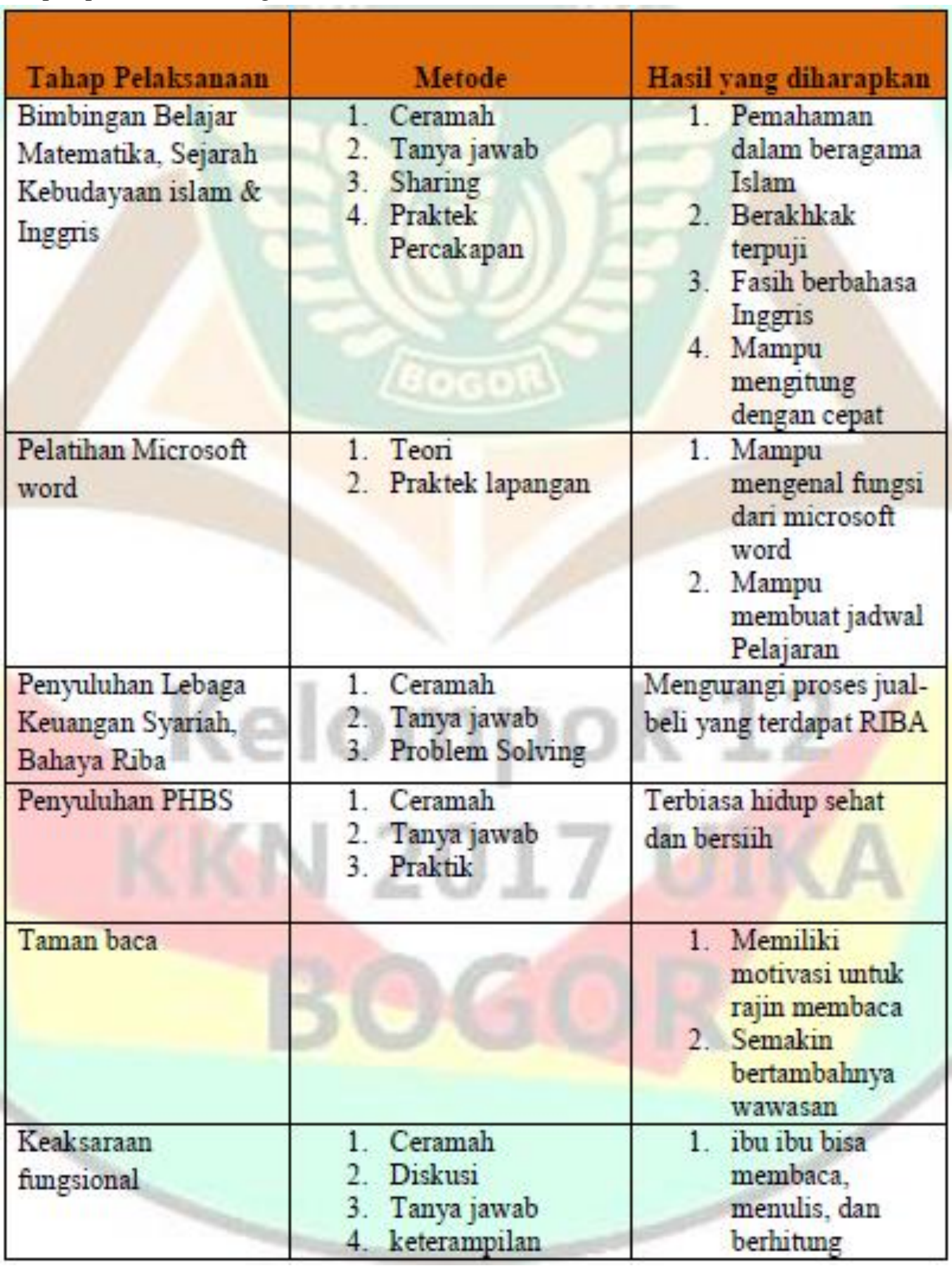




\begin{tabular}{|c|c|c|}
\hline $\begin{array}{l}\text { Penyuluhan Gizi } \\
\text { Seimbang }\end{array}$ & $\begin{array}{l}\text { 1. ceramah } \\
\text { 2. tanya jawab }\end{array}$ & \\
\hline $\begin{array}{l}\text { Penyuluhan Manfaat } \\
\text { buah dan sayur }\end{array}$ & $\begin{array}{l}\text { Ceramah } \\
\text { Tanya jawab }\end{array}$ & $\begin{array}{l}\text { 1. Untuk } \\
\text { meningkatkan } \\
\text { pengetahuan } \\
\text { abak-anak akan } \\
\text { pentingnya } \\
\text { mengknsumsi } \\
\text { buah dan sayur } \\
\text { 2. Badan sehat } \\
\text { tumbuh dan } \\
\text { berkembang } \\
\text { dengan baik }\end{array}$ \\
\hline $\begin{array}{l}\text { Penyuluhan } \\
\text { Menabung sejak dini }\end{array}$ & $\begin{array}{l}\text { 3. Ceramah } \\
\text { 4. Praktik }\end{array}$ & $\begin{array}{l}\text { 5. Anak-anak } \\
\text { paham } \\
\text { bagaiaman } \\
\text { pentingnya } \\
\text { menabung }\end{array}$ \\
\hline Ekonomi kreatif & $\begin{array}{l}\text { 1. Ceramah } \\
\text { 2. Praktik }\end{array}$ & $\begin{array}{l}\text { 6. Masyarakat } \\
\text { mampu } \\
\text { memanfaatkan } \\
\text { barang-barang } \\
\text { bekas } \\
\text { 7. Tbu-ibu lebih } \\
\text { kreatif }\end{array}$ \\
\hline $\begin{array}{l}\text { Penyuluhan Nikah } \\
\text { sirih }\end{array}$ & $\begin{array}{l}\text { 1. ceramah } \\
\text { 2. tanya jawab }\end{array}$ & $\begin{array}{l}\text { 1. Masyarakat desa } \\
\text { pamegarsari } \\
\text { mengetahui } \\
\text { bahwa nikah } \\
\text { sirih sah secara } \\
\text { Agama, tetapi } \\
\text { tidak sah scara } \\
\text { hukum. } \\
\text { 2. Mengetahui } \\
\text { akibat dari nikah } \\
\text { sirih terutama } \\
\text { bagi istri dan } \\
\text { anak. }\end{array}$ \\
\hline Bazar & $\begin{array}{l}\text { 1. Jual baju layak } \\
\text { pakai } \\
\text { 2. Sembako }\end{array}$ & $\begin{array}{l}\text { Membantu } \\
\text { ekonomi } \\
\text { masyarakat }\end{array}$ \\
\hline
\end{tabular}


Jadwal Kegiatan

\begin{tabular}{|c|c|c|c|c|}
\hline \multirow{2}{*}{ No. } & \multirow{2}{*}{ Kegiatan } & \multicolumn{3}{|c|}{ Bulan } \\
\hline & & Juli & Agst & Sept \\
\hline 1. & Penyusunan Rencana kegiatan & & & \\
\hline 2. & Sosialisasi rencana kegiatan & & & \\
\hline 3. & Survei Lokasi & & & \\
\hline 4. & Silaturahim Tokoh dan Masyarakat & & & \\
\hline 5. & Bimbingan Belajar & & & \\
\hline 6. & Pengajaran di MI Miftahul Athfal & & & \\
\hline 7. & Pelatihan Microsoft & & & \\
\hline 8. & Ekonomi kreatif & & & \\
\hline 9. & 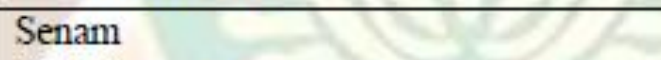 & & & \\
\hline 10 & Penyuluhan Bahaya Riba & & & \\
\hline 11 & Penyuluhan Pentingnya menabung & & & \\
\hline 12 & Penyuluhan Gizi seimbang & & & \\
\hline 13 & Penyuluhan PHBS & & & \\
\hline 14 & Penyuluhan Nikah sirih & & & \\
\hline 15 & Penyuluhan kesehatan lingkungan & & & \\
\hline 16 & Penyuluhan bahaya teknologi & & & \\
\hline 17 & Pemberian Vitamin A & & & \\
\hline 18 & Suntik Rubela di MI Miftahul Athfal & & & \\
\hline 19 & Penyuluhan Manfaat buah dan sayur & & & \\
\hline 20 & Launching Taman Baca & & & \\
\hline 21 & Keaksaraan Fungsional & & & \\
\hline 22 & HUT RI & & & \\
\hline 23 & Bazar & & & \\
\hline 24 & Sumbangan Buku & & & \\
\hline 25 & Bagi-bagi sembako untuk peserta KF & & & \\
\hline 26 & $\begin{array}{l}\text { Pemasangan poster Bahaya Narkoba, } \\
\text { PHBS, Lingkungan sehat, adab di masjid }\end{array}$ & & & \\
\hline 27 & Penutupan KKN & & & \\
\hline
\end{tabular}

\section{Metode Pendekatan}

Dalam melaksanakan penelitian ini kami menggunakan jenis penelitian yang bersifat field research atau penelitian lapangan yaitu penelitian yang dilakukan langsung kelapangan atau terjun langsung kemasyarakat Desa Pamegarsari untuk memperoleh data-data yang dibutuhkan. Kamipun melakukan penelitian berdasarkan analisis data yang didapatkan dari Lembaga/Aparatur Desa (Kantor Kepala Desa) dan juga para tokoh agama.
Dalam metode pendekatan ini kami menggunakan beberapa pendekatan antara lain:

Pendekatan Sosiologis: Pendekatan ini bertujuan untuk mengetahui kondisi kehidupan masyarakat sehari-hari.

Pendekatan Psikologis: Pendekatan ini bertujuan untuk melihat kondisi yang menjadi objek penelitian. Adapun metode yang digunakan dalam pengumpulan data yang kami gunakan yaitu dengan observasi langsung kehidupan sehari-hari masyarakat 
di Desa Pamegarsari, kemudian kami juga menggunakan metode wawancara dengan para tokoh agama setempat, dan dalam pengumpulan data ini ada beberapa sumber data yang penulis kumpulkan yaitu :

Data yang bersifat primer yaitu suatu data yang kami dapatkan dari sumbersumber yang terpercaya seperti aparatur desa dan tokoh agama masyarakat desa Gadog. Populasi dan Sampel. Adapun populasi dan sampel yang dijadikan penelitian ini adalah masyarakat rt 04dan 5/03 Desa Pamgarasari. Analisis data yang di gunakan adalah data kualitatif yang dilakukan sejak sebelum memasuki lapangan, selama di lapangan dan selesai di lapangan, namun dalam menganalisa data lebih di fokuskan selama proses di lapangan bersamaan dengan pengumpulan data.

\section{Partisipasi Masyarakat dalam Pelaksanaan Program}

Partisipasi masyarakat yang dapat dilakukan dalam kegiatan ini adalah sebagai berikut:

1. Kepala Desa dan staff membantu mencari tempat hunian selama KKN

2. Bersama ibu RW mencai peserta keaksaraan fungsional

3. Mengizinkan dan mendukung anakanak untuk mengikuti Bimbingan Belajar

4. Mempersiapkan tempat untu penyuluhan

5. Bersama dengan pemuda menyusun lomba dalam rangka memperingati hari kemerdekaan

6. Mengji dan belajar bersa dengan ibu-ibu majelis ta'lim

7. Mengizinkan dan mendukung pemasangan spanduk

8. Mempersiapkan alat kebersihan dan kerja bakti bersama
9. Mempersiapkan tempat untuk Bazar

\section{Langkah Evaluasi}

Evaluasi yang akan dilakukan terdiri dari:

1) Evaluasi proses, yang terkait dengan perencanaan, pelaksanaan dan monitoring kegiatan. Evaluasi proses akan dilakukan setiap pekan bersama dengan kelompok.

2) Evaluasi hasil, yang akan dilaksanakan setelah kegiatan dilaksanakan. Evaluasi hasil bertujuan untuk mempertimbangkan gaenda-agenda yang akan dilaksanakan selama KKN berlangsung.

\section{REALISASI PROGRAM}

\section{Program Bidang Pendidikan}

a. Bimbingan Belajar

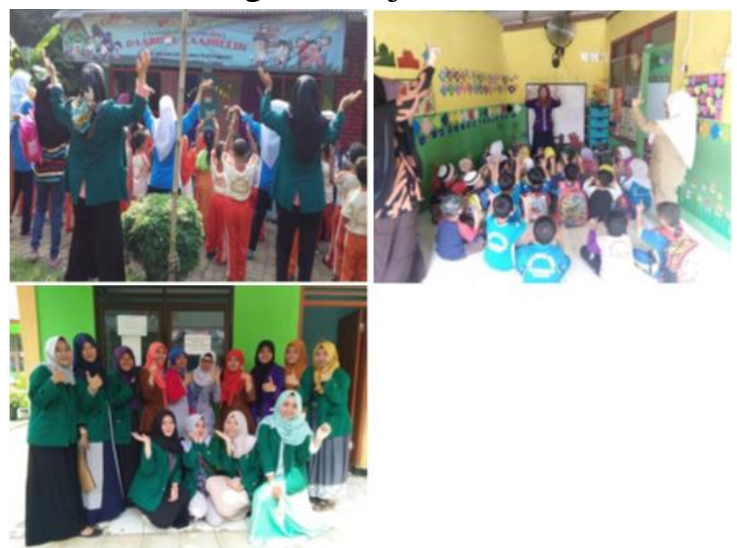

b. Pengajaran di MI Miftahul Athfal

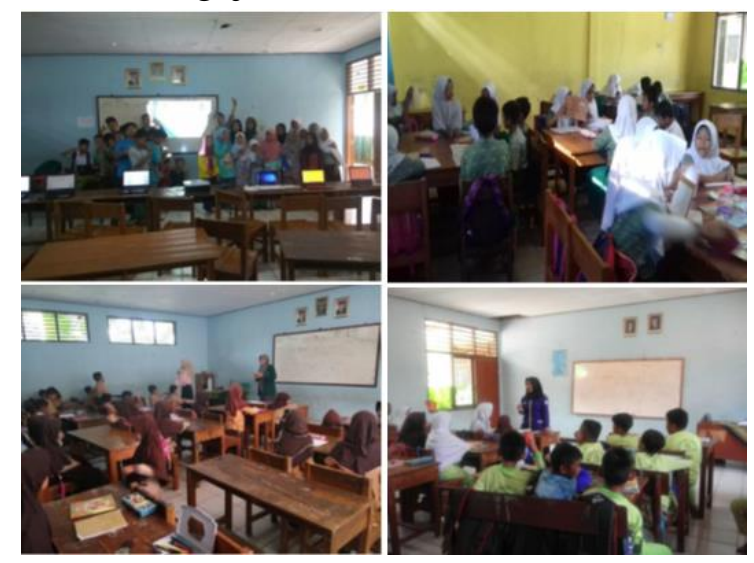

c. Pelatihan Microsoft 


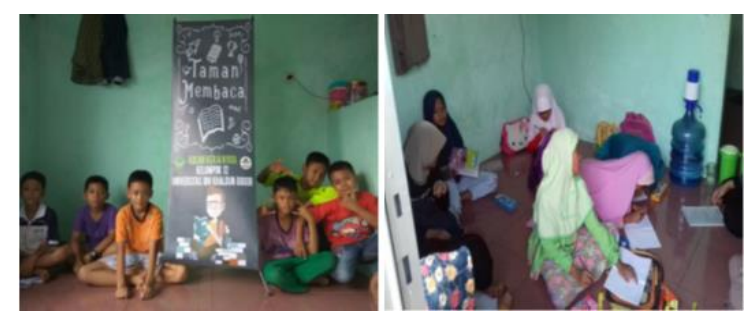

d. Taman Baca

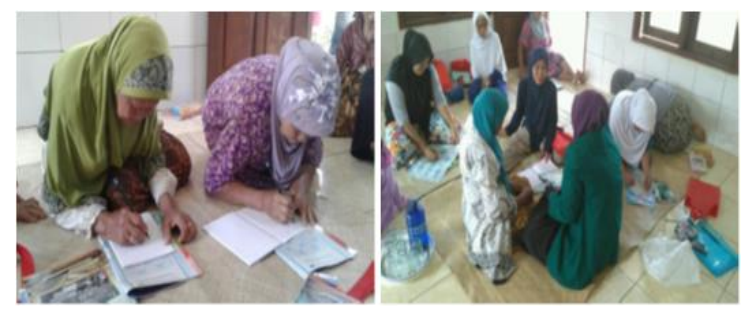

e. Keaksaraan Fungsional

f. Penyuluhan Nikah sirih

g. Penyuluhan bahaya teknologi

\section{Program Bidang Lingkungan}

a. HUT RI
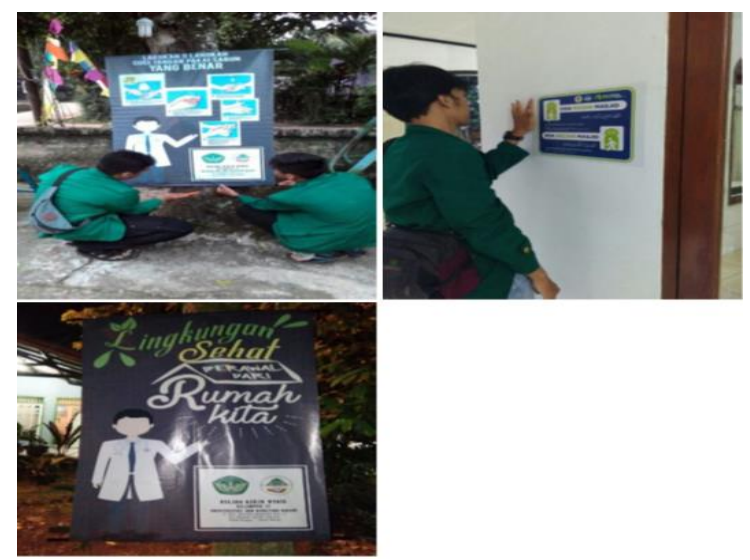

b. Pemasangan poster Bahaya Narkoba, PHBS, Lingkungan sehat, adab di masjid

\section{Program Bidang Ekonomi}

a. Ekonomi kreatif

b. Penyuluhan Bahaya Riba
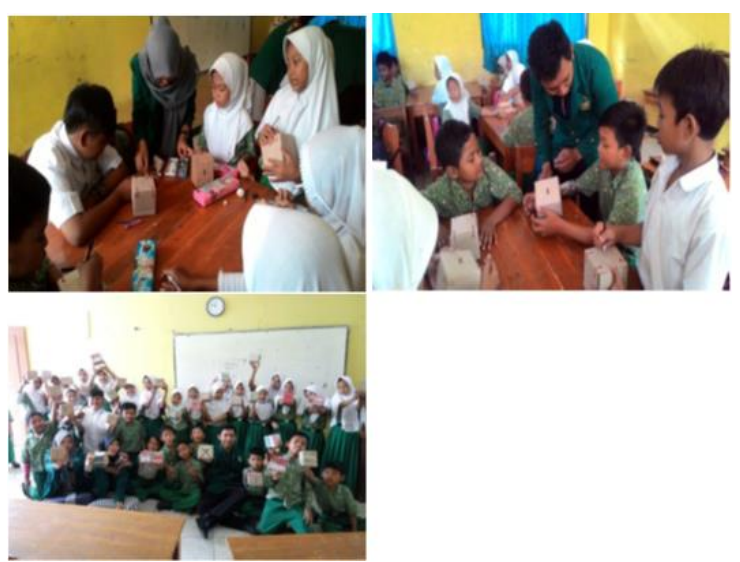

c. Penyuluhan Pentingnya menabung

d. Bazar

e. Sumbangan Buku

f. Bagi-bagi sembako untuk peserta KF

\section{Program Bidang Kesehatan}
a. Senam
b. Penyuluhan Gizi seimbang
c. Penyuluhan PHBS
d. Penyuluhan kesehatan lingkungan
e. Pemberian Vitamin A
f. Suntik Rubela di MI Miftahul Athfal
g. Penyuluhan Manfaat buah dan sayur

\section{KESIMPULAN}

Sasaran Program melingkupi berbagai usia baik anak-anak, pemuda, setengah baya maupun orang tua, baik laki-laki maupun perempuan, baik dari kalangan pelajar sekolah, guru, buruh, ibu rumah tangga dan lain sebagainya.

Sehingga dapat disimpulkan bahwa program diapresiasi dengan baik oleh masyarakat dan sukses terselenggara atas bantuan dan dukungan dari berbagai pihak terutama oleh Ketua Rw yaitu Bapak Bambang Sdan Kepala Desa Bapak Ahmad Djamaludin, SE., MM.

Semua ini dirasakan sebagai berkah dari kesungguhan dan kerja keras serta kekompakan dari anggota kelompok 12 
KKN Tematik Terintegrasi UIKA, serta kontribusi masyarakat sekitar.

\section{Dampak Bagi Masyarkat}

Masyarakat di Desa pamegarsari terutama ibu-ibu kini tidak malu untuk belajar membaca, menulis dan berhitung, ibu-ibu di Desa pamegarsari semangat untuk menuntut ilmu. Dengan kami terjun langsung ke sekolah selama 1 bulan, baik siswa, pihak sekolah dan masyarakat merasa sennag, karena siswa siswi yang memiliki keterlambatan dalam belajar dapat di bimbing secara personal oleh kami, kami juga mmebantu prosese perayaan HUT RI di Desa Pamegarsari, khusunya di RW 03, masyarakat merasa terbantu dengan ide dan tenaga yang kita beri, karean mayoritas penduduk di sana sibuk bekerja sehinggi minim partisipasinya terhadap acara-acara yang dilaksanakan di desa.

\section{SARAN}

\section{Rekomendasi untuk SDN 05 Gadog}

Untuk menangani fasilitas yang kurang memadai di MI Miftahul Athfal 01 Pamegarsari, maka guru sebagai pengajar perlu lebih kreatif untuk mentransfer ilmu kepada rapa peserta didik, agar ilmu yang disampaikan tetap sampai secara utuh.

Sebaiknya guru diikutkan dalam seminar-seminar atau pelatihan terkait bagaimana memanfaatkan alam sekitar sebagai sumber belajar dan media pembelajaran.

\section{Ekomendasi untuk Pemerintah Desa} Megamendung

Untuk meningkatkan SDM di RW

03, hal yang direkomendasikan kepada

Kepala Desa adalah sebagai berikut: a. Membangan klinik kesehatan diantara wilayah RW 1-5 agar memudahkan masyarakat mendapatkan pertolongan pertama.

b. Pembuatan usaha melalui bahan-bahan daur ulang agar lebih memanfaatkan sampah-sampah plastik yang ada disekitar RW 03 


\section{REFERENSI}

Administrasi Profil Desa Jabon Mekar

Fahmi eroby, 2008, Pendidikan berbasis masyarakat. Yogyakarta

LPPM ; Universitas Ibn Khaldun Bogor;. (2017). Petunjuk Pelaksanaan KKN Tematik Terintegrasi 2017. 